\title{
Línguas estrangeiras e outras relações possíveis com a escola pública
}

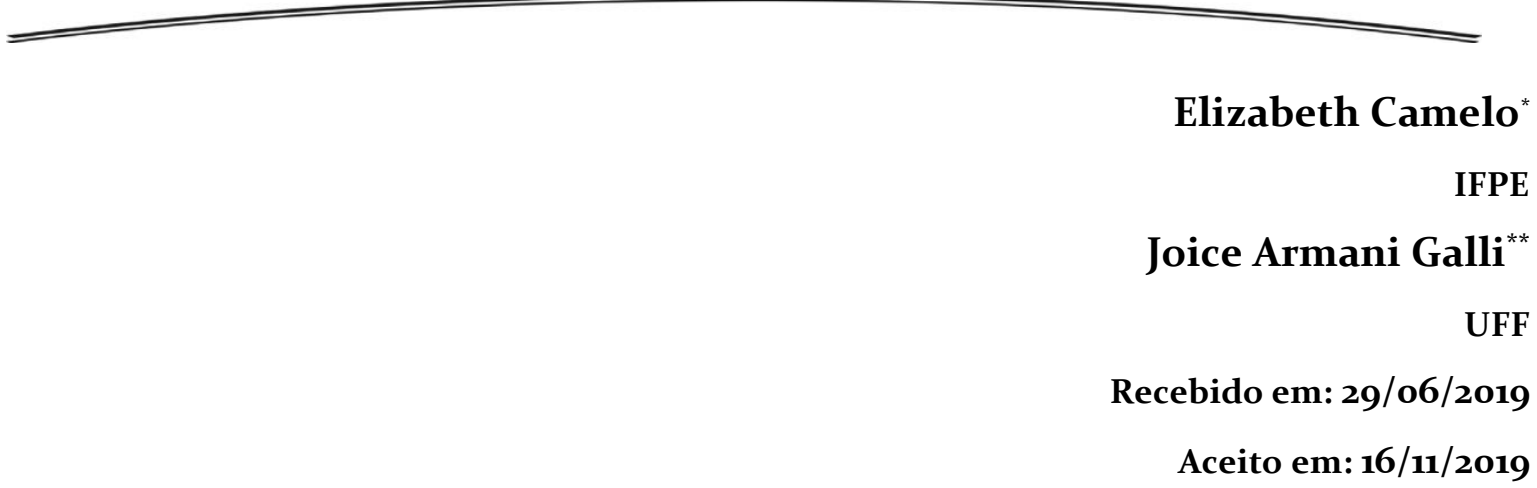

Resumo: A construção do conhecimento linguístico na educação brasileira tem sido uma temática necessária para a reflexão sobre políticas de formação cidadã. Tendo em vista o cenário atual, que traz desafios ao ensino e aprendizagem de Línguas Estrangeiras (LE), principalmente para a Educação Básica, objetiva-se discorrer sobre possibilidades diversas de relação entre línguas e escola pública. A partir da leitura da BNCC (2017), propomos a discussão de questões relativas à formação docente e ao trabalho com LE na perspectiva do letramento, apoiando-nos em Street (2014) e Soares (2017). No que tange a políticas linguísticas, valemo-nos de Calvet (2007) e Rajagopalan (2011).

Palavras-chave: Letramento. Línguas Estrangeiras. Políticas Linguísticas. Escola Pública.

Abstract: The construction of linguistic knowledge in Brazilian education has been a necessary theme for the reflection on citizen formation policies. Given the current scenario, which brings challenges to the teaching and learning of foreign languages (LE), especially for basic education, the objective is to discuss about different possibilities of relationship between languages and public school. From the reading of the BNCC (2017), we propose the discussion of issues related to teacher education and working with LE from the perspective of literacy, supporting us in Street (2014) and Soares (2017). Regarding language policies, we use Calvet (2007) and Rajagopalan (2011).

Key-words: Literacy. Foreign Languages. Language Policies. Public School.

Résumé: La construction de savoirs linguistiques dans l'éducation brésilienne est devenue de plus un plus un sujet pertinent à la réflexion autour de politiques sur la formation citoyenne. Plus précisément, à l'heure actuelle le scénario présente des défis pour l'enseignement-apprentissage de Langues Étrangères (LE) notamment dans l'Éducation Élémentaire. Ceci dit, l'objectif de cet article est de discuter d'autres démarches possibles dans le rapport langues et école publique. Pour ce faire, nous parlerons de la formation d'enseignants et l'approche de la littératie d'après Street (2014) et Soares (2017). Le cadre théorique est également celui des politiques linguistiques selon Calvet (2007) et Rajagopalan (2011). Mots-clé: Littératie. Langues Étrangères. Politiques Linguistiques. École Publique. 


\section{Introdução}

As relações entre a academia e a escola e, guardadas as devidas proporções, entre o conhecimento e a sociedade, são fontes de inúmeras formações, congressos, seminários, enfim de eventos acadêmicos e educacionais que visam ao estreitamento desses universos, às vezes, paralelos. A Era da Informática, sob algumas perspectivas, veio aumentar essa distância e acirrar o diálogo sempre necessário entre teoria e prática. A partir de noções acerca do Letramento em Línguas Estrangeiras (LE) e políticas públicas em LE no Brasil, o presente artigo pretende discorrer sobre a relação há pouco evocada, particularmente na área das Letras. Cabe ressaltar que, por serem campos afins, Educação e Letras implicam permanente diálogo sobre seu fazer pedagógico, principalmente, na esfera da Educação Básica, cabendo a cada área sua atuação crítica e social. Será, portanto, a partir da formação em Letras e a especificidade das LE em sua inserção na escola pública que se debruçará a presente reflexão.

No que tange ao mundo virtual e à formação de professores, que parece estar sempre aquém da velocidade com a qual os estudantes lidam com a tecnologia, consideramos que uma breve escapada no tempo contribua para entender a essencialidade do papel do professor. Daí focarmos nosso artigo na formação docente como um pilar fundamental para avanços em políticas públicas de LE.

Quando o Século XIX trouxe a revolução da imagem através da criação do daguerreotipo, primeiro aparelho fotográfico inventado por Daguerre em 1839, na França, tal descoberta, apesar de louvável, representou uma crise para os pintores da época. Como é do ser humano a necessidade de ficção, muito mais que a simples reprodução da realidade, um grupo de artistas fundaria, logo a seguir, o movimento nas artes que seria reconhecido e apreciado no mundo inteiro até o presente: o Impressionismo. Essa escola de arte desenvolveu a precisão paradoxal de captar imagens, sobretudo paisagens, cujo efeito poderia ser registrado somente pelas mãos e sua dança com pincéis, já que a falta de nitidez de tal modo impressa, jamais poderia ser copiada ou registrada por um aparelho fotográfico.

Assim é o movimento de ensino de línguas na contemporaneidade. Nenhum aplicativo, site ou sistema virtual pode prescindir da condução de um professor, de um profissional das línguas com formação e experiências que assegurem a integração, sobretudo afetiva que ainda não é possível de ser garantida por qualquer mecanismo que 
não seja o mecanismo humano, responsável por articular processos cognitivos e emocionais para a aquisição do conhecimento em uma LE. A despeito de não ser o objetivo do presente artigo, vale destacar que o fator emocional desempenha um papel determinante na construção do conhecimento em línguas. Voltando-nos objetivamente a nossa proposta, pensamos que algumas seções na escrita desse artigo possam organizar melhor a presente produção acadêmica.

Dessa forma, entendemos que seria interessante trazer uma parte, ainda em torno da introdução ao tema, resgatando brevemente a trajetória da formação de professores de LE nos últimos anos. Ao traçarmos tal panorama, daremos especial destaque ao programa do governo federal Idiomas sem Fronteiras (IsF), porque se apresentará aqui como pano de fundo, a fim de trazermos a realidade de dois estados distantes geograficamente, mas próximos nas lutas de vanguarda no que se refere às políticas linguísticas de LE: Pernambuco e Rio Grande do Sul. Partindo-se, então, desse desenho metodológico, apresentamos as duas seções que discorrerão sobre o ensino de Inglês na rede pública estadual de Pernambuco e o ensino de Francês na rede municipal de ensino (RME) de Porto Alegre, sua implantação e continuidade na última década. A seguir, propomos um capítulo central no que diz respeito a outras relações possíveis entre LE e escola pública, discutindo a Base Nacional Comum Curricular (BNCC) e rechaçando o modelo privado como referência a algo que entendemos ser dever da Educação Básica.

Na perspectiva de Letramento em LE, as línguas são vetores culturais responsáveis por armazenar a memória e valores humanitários nucleares na constituição de sociedades menos desiguais. Isso posto, finalizaremos com reflexões sobre a pertinência da defesa do ensino de línguas na escola pública brasileira, sob a vertente teórica do Letramento para construção de ações em torno de políticas públicas para as LE.

\section{O Programa Idiomas sem Fronteiras: uma tentativa de alinhar pesquisa linguística e formação docente em tempos de globalização}

Pensamos que títulos como o reconhecimento à formação docente que o primeiro programa de línguas nacional, o Idiomas sem Fronteiras (IsF) atribuiu aos professores, estabelecendo uma efetiva rede de profissionais, mereça ser comentado. Embora a concessão de bolsas de apoio financeiro só tenha chegado ao Inglês, justificado pelos 
números atendidos, o Francês, em sua luta de décadas, teve no Francês sem Fronteiras (FsF) a oportunidade de criar uma rede para as discussões acerca dessa LE. Além disso, as outras cinco línguas do programa, quais sejam: Espanhol, Italiano, Alemão, Japonês e o próprio Português para estrangeiros (PLE) também gozaram de um período de discussão e maior unidade enquanto áreas de atuação.

Não por acaso, a maior crítica ao programa vinha da parte dos colegas de Espanhol, como veremos a seguir. Tendo nascido para atender a demanda do Ciências sem Fronteiras $(\mathrm{CsF})$ em 2011, o programa inicialmente intitulado "Inglês sem Fronteiras" trouxe à cena a importância do conhecimento de línguas como constituinte à formação de estudantes que partiam para mobilidade. Não sendo mais complementar, mas condição sine qua non para a inserção do Brasil no mapa político da internacionalização, as línguas gozaram de um período de efetivo crescimento e investimento, sobretudo na formação docente. Inúmeros eventos acadêmicos, congressos e pesquisas linguísticas se difundiram na primeira parte da presente década.

Em paralelo, estava prevista igualmente a implementação do Espanhol como LE obrigatória a partir de 2010, previsão que não se consolidou bem como foi apagada da Lei de Diretrizes e Base da Educação Nacional (LDBEN) 9394/96 a possibilidade de inserção de uma LE, que não somente o Inglês. Ao excluírem-se as demais línguas, tal legislação não atende aos anseios da comunidade escolar, que poderia optar pelo Espanhol, por exemplo, língua predominante da América Latina. No espaço atribuído à possibilidade de línguas, foi arbitrariamente colocado o Inglês como única e possível LE, por atender as demandas do mercado de trabalho, o que também destoa da realidade se pensarmos sob o ponto de vista das relações econômicas do Brasil no MERCOSUL. A não pluralidade de línguas foi reforçada pela Base Nacional Comum Curricular (2017) como será constatado ao longo do trabalho.

Nesse sentido, a crítica dos professores de Espanhol, que não viam no programa IsF uma ação de retroalimentação aos cursos de Letras, ou seja, não reconheciam um efetivo investimento na base de LE por parte desse programa governamental, que deveria privilegiar inicialmente a Educação Básica, acaba sendo consolidada quando a Lei Número 11.165, de 2005, que versava sobre a obrigatoriedade do Espanhol, foi revogada. Tal crítica resta, portanto, pertinente uma vez que, em particular essa língua, a língua do antagonista de Portugal no período das navegações e da expansão linguística, também foi Revista Investigações, Recife, v. 32, n. 2, p. 456 - 478, Dezembro/2019 
a maior prejudicada frente ao retrocesso apresentado pelo apagamento explícito da já citada LDBEN, vindo a somar-se ao quadro de retrocessos impostos pela BNCC no que tange a políticas públicas de LE no Brasil. Nesse sentido cabe citar que:

Essa medida acompanha uma virada radical na política externa brasileira, que passou a dar as costas à América Latina e ao Mercosul para se alinhar diretamente com os Estados Unidos, e tem estreita relação com outras medidas econômicas e comerciais que consideram estratégico o uso do Inglês, enquanto língua global dos negócios (LAGARES, 2018, p. 67).

A necessidade em debater a construção do conhecimento linguístico em línguas em nosso país é um tema bastante particular devido à série de variantes que a envolvem, desde fatos culturais até econômicos, constituindo um cenário político tenso. Igualmente complexas são as áreas que a discutem, havendo desde a Linguística Aplicada (LA) e os Multiletramentos apenas para citar dois campos em que se debruça a construção desse conhecimento linguístico. Situamos, no entanto, a presente produção com referência aos processos de ensino e aprendizagem das LE, sustentando o arcabouço teórico no letramento social através de autores como Street (2014), Soares (2017) e Galli (2017a). Objetivamos comentar sobre a pesquisa linguística nessa área e sua relação com a formação docente, já que como salientado, o papel do professor de línguas é fundamental para os avanços do processo de políticas públicas de línguas no território nacional.

Ainda que haja tantos outros elementos na paisagem do ensino e aprendizado de línguas: como o aluno, o programa escolar, as condições estruturais educativas, não será sobre tais elementos que pretendemos voltar nosso olhar neste momento, por entendermos a urgência em tratar da formação docente e sua relação na construção do conhecimento linguístico na esfera da escola pública. Sob tal recorte, parece-nos pertinente estabelecer paralelos entre o que a academia produz em termos de conhecimento no campo da pesquisa linguística e o que acontece na escola pública.

Propomos assim lançar um olhar sobre o percurso histórico do lugar das LE na Educação Básica do estado de Pernambuco, os documentos norteadores, o ensino de LE e sua relação com as escolas estaduais, além do novo desenho curricular à luz da BNCC. Logo a seguir, na perspectiva de contrapor outra legislação central para as políticas linguísticas nacionais, a já mencionada LDBEN 9394/96, traremos sob a forma de relato como se deu a implantação de duas línguas de imigração (Italiano e Alemão) e a 
continuidade de três LE, quais sejam: o Inglês, o Espanhol e o Francês na RME da capital do Rio Grande do Sul.

\section{O ensino de Inglês em Pernambuco/Recife}

O processo de ensino e aprendizagem de LE tem sido objeto de reflexão e estudos nos mais diversos contextos e instituições, como abordamos inicialmente. Considerando que a aprendizagem de uma LE deve ser significativa e atender às necessidades do aprendiz/aprendente, uma vez que o mesmo tem por motivação a utilização desse conhecimento na sua vida cotidiana (LIBERALI, 2009), é de fundamental importância tratar desse processo no contexto da Educação Básica pública, a fim de entender quais seriam os impactos na vida social dos estudantes.

O ensino de LE na educação de base apresenta um percurso de luta para se sustentar nos currículos como disciplina. No decorrer da história foi ofertado o ensino de algumas LE clássicas como o Grego e o Latim e, posteriormente, foram tomando seu lugar as LE modernas como Francês, Inglês, Alemão e Italiano. Embora tenham sido oferecidas, enfrentavam algumas questões problemáticas como a metodologia de ensino e a carga horária que lhes eram destinadas, pois as instituições ficavam responsáveis por determinar os objetivos de se ensinar as diversas línguas e o tempo necessário para se desenvolver as competências consideradas essenciais.

Apesar de ter seu lado positivo, o da autonomia local, restava ainda uma lacuna em termos de perspectiva nacional para o ensino e aprendizado das LE, carecendo de maior debate desde os propósitos de se incluir este conhecimento na escola pública e as metodologias de ensino adotadas. Segundo Leffa (1999), a "burocratização" das funções da escola no que diz respeito às LE, fez com que as escolas passassem a se preocupar mais com a aprovação e fornecimento de diplomas do que com o processo de ensino e aprendizagem.

Com as reformas educacionais ocorridas no país, dentre elas a reforma Capanema e as LDB (como era nomeada até fins da década de 9o), o ensino de LE foi se firmando nos currículos da Educação Básica, considerando que em algumas dessas reformas foi dada aos estados e, mais particularmente, aos municípios da federação, uma certa autonomia 
na oferta de LE em seus currículos. Com isso, cada esfera da educação básica foi se posicionando em relação à escolha das línguas a serem contempladas, sua obrigatoriedade, seus objetivos e carga horária, buscando assim dar maior sustentação e identidade às LE enquanto disciplina.

Tratando mais especificamente do estado de Pernambuco, algumas medidas foram tomadas para uma maior valorização do ensino de LE antes mesmo do surgimento de documentos orientadores como a LDB no 9394/96 e os PCN - Ensino Fundamental (1998) e Ensino Médio (200o). Em Pernambuco foram criados os primeiros Núcleos de Estudos de Línguas (NEL) no início da década de 9o, ofertando inicialmente Língua Inglesa e Língua Francesa ${ }^{1}$, estando esses Núcleos em funcionamento até hoje com a oferta de mais duas línguas: Espanhol e Alemão. Já na criação dos NEL se reconhecia a preocupação do Estado em oferecer um ensino de LE de qualidade, pois são cursos oferecidos gratuitamente para toda a comunidade escolar (estudantes, professores, funcionários e comunidades circunvizinhas à escola). É importante salientar que os NEL não foram criados para substituir as aulas de LE no ensino regular, pois logo após a criação dos mesmos, surgiu um material didático e pedagógico chamado Coleção Professor Carlos Maciel (1997), que trazia orientações para o ensino de Língua Inglesa (LI) e de outros componentes curriculares nos ensinos fundamental e médio da rede pública estadual de educação.

Constata-se assim que o estado de Pernambuco demonstra desde cedo sua preocupação com o ensino e aprendizagem de LE, tendo em vista que além dos documentos próprios criados pelo estado e para o estado, a Secretaria de Educação sempre esteve em consonância com os documentos nacionais como os Parâmetros Curriculares Nacionais (PCN), de 1998, e as Orientações Curriculares para o Ensino Médio (OCEM), de 2006. Com base em tais documentos, a Secretaria de Educação publicou, em 2009, as Orientações Teórico-Metodológicas (OTM) para o ensino na rede, documento norteador das práticas metodológicas nas salas de aula dos diversos componentes curriculares.

Os documentos mais recentes produzidos pela Secretaria de Educação são os Parâmetros para Educação Básica do Estado de Pernambuco (2013), os quais estão

\footnotetext{
1 Para maior delineamento dos NEL quanto à língua francesa, sugere-se o artigo de Aubin \& Galli (2015), na Revista Internacional Le Français Dans Le Monde, conforme referências ao final deste artigo. Revista Investigações, Recife, v. 32, n. 2, p. 456 - 478, Dezembro/2019
} 
organizados em Parâmetros Curriculares para cada componente curricular e, no caso mais específico das LE, foram elaborados os Parâmetros Curriculares de Língua Inglesa e os Parâmetros Curriculares de Língua Espanhola. Ambos foram produzidos com a colaboração de membros da própria Secretaria, representantes das universidades e consultores especialistas da área de ensino de LE. O processo de elaboração dos documentos contou com várias leituras e discussões acerca do ensino e aprendizagem da Língua Inglesa e Língua Espanhola, discussões que também tiveram a participação de alguns professores de LE da rede, pois, após escritas às versões iniciais do documento, o mesmo era encaminhado às escolas para consulta dos professores da área que sugeriam alterações, as quais eram consideradas na elaboração das versões subsequentes. Assim, para a construção dos Parâmetros Curriculares de Língua Inglesa e os de Língua Espanhola houve a participação majoritária de sujeitos envolvidos no processo de ensino e aprendizagem de LE.

A produção coletiva dos Parâmetros Curriculares para a Educação Básica do estado de Pernambuco também encontrou entraves nas questões relativas à concepção teórica, uma vez que a criação de um documento norteador da composição curricular das disciplinas para a Educação Básica necessitava se posicionar teoricamente. Com isso, após leituras e discussões, adotou-se uma perspectiva interacionista e dialógica da linguagem, orientando assim a abordagem recomendada para o trabalho com as LE nas salas de aula, diferente da concepção nacional que vislumbrava mais uma abordagem comunicativa.

Como os próprios Parâmetros apresentam em algumas citações, a língua é vista como "um conjunto de práticas sociais e cognitivas historicamente situadas" (MARCUSCHI, 20o8, p.61), passando a ser compreendida como o principal meio pelo qual os indivíduos agem socialmente, adequando seus discursos aos contextos sociais nos quais estão inseridos. E esse agir socialmente deve ser o foco do tratamento com a língua na perspectiva do ensino e aprendizagem, pois pode-se ver na realidade do estado de Pernambuco, com a produção de documentos oficiais norteadores do ensino de línguas, que a linguagem está intimamente ligada ao contexto social de interação, assim como apresentam os Parâmetros para a Educação Básica de Pernambuco, documento o qual, baseado em uma concepção de linguagem interacional, afirma que: 
[..] o aprendizado da língua vai muito além do domínio de estruturas gramaticais e textuais. Ele envolve o desenvolvimento das capacidades de ler, escrever, falar, ouvir, além da capacidade de analisar a língua. Ademais, por sua natureza social, o aprendizado da língua envolve um saber agir no mundo via linguagem (2013, p.13).

Nessa perspectiva, a língua se desenvolve num contexto sócio-histórico e cultural, sendo também considerada como o lugar da manifestação ideológica, tendo em vista que é por meio dela que significamos a realidade de diversas formas. Naquilo que Street (2014) descreve como "Novos Estudos de Letramentos", pode-se perceber essa perspectiva ideológica dos letramentos que, segundo o autor, é vista como "prática envolvida em relações de poder e incrustada em significados e práticas culturais específicos" (STREET, 2004, p.17). Sendo, portanto, nesse contexto que os sujeitos se constroem discursivamente, bem como trata-se dos sentidos que também são construídos nas relações de interação nos diversos contextos comunicativos.

Muito embora as concepções de língua e linguagem estivessem bem definidas nos documentos norteadores do ensino e aprendizagem de LE em PE, o surgimento da BNCC (2017) vem para trazer uma reavaliação dos currículos de todas as disciplinas. Em vista disso, sendo a BNCC um documento que se coloca como normativo e norteador dos currículos para a Educação Básica dos sistemas e redes de ensino do país, as propostas curriculares de todos os estados precisaram ser revisitadas e, em alguns casos, até modificadas para atender ao que propõe o documento maior - a Base.

A BNCC do Ensino Infantil e Fundamental define um conjunto de aprendizagens essenciais para o desenvolvimento de competências gerais necessárias para a formação de um patamar comum de aprendizagens para os estudantes de todo o país, o que coloca a população brasileira num mesmo nível de conhecimento e necessidades de aprendizagem. Com o objetivo de sanar tal leitura dos objetivos educacionais das diversas redes de ensino, a Base propõe uma reelaboração curricular pelos estados e municípios brasileiros, a fim de contemplar as especificidades de cada região. Configura-se o presente período como o momento em que secretarias estaduais e municipais de educação do país se organizam para discutir e repensar suas propostas curriculares. E nesse processo de reorganização curricular, retomam-se as discussões acerca das concepções de língua e linguagem que, no caso de Pernambuco, precisaram ser revisitadas. Haja vista que a proposta de uniformização da BNCC se distancia do que preconizavam os documentos 
norteadores do ensino de LE no estado pernambucano, questionamos o fato de que sua abordagem restrinja-se à língua enquanto instrumento, concepção teórica que data das décadas de 80 e 90 no Brasil, em que o ensino e aprendizado de LE acontecia em nível instrumental.

Dentre as aprendizagens ditas essenciais as quais são propostas pela Base, a Linguagem se enquadra na competência 4 , a qual se caracteriza pela:

Utilização de diferentes linguagens - verbal (oral ou visual-motora, como Libras, e escrita), corporal, visual, sonora e digital - bem como conhecimentos das linguagens artística, matemática e científica, para se expressar e partilhar informações, experiências, ideias e sentimentos em diferentes contextos e produzir sentidos que levem ao entendimento mútuo (BNCC, 2017, p.9).

Segundo o que propõe esse documento para os currículos de LE, a finalidade de se trabalhar linguagem na Educação Básica é:

Possibilitar aos estudantes participar de práticas de linguagem diversificadas, que lhes permitam ampliar suas capacidades expressivas em manifestações artísticas, corporais e linguísticas, como também seus conhecimentos sobre essas linguagens, em continuidade às experiências vividas na Educação Infantil (BRASIL, 2017, p.61, grifo nosso).

Dessa forma, percebe-se uma preocupação maior em desenvolver habilidades de comunicação e expressão para participação em práticas de linguagem, do que construir a própria prática. Considerando que todos os sujeitos agem socialmente no mundo por meio da linguagem, não sendo, portanto, meros expectadores, questionamos mais uma vez como seria possível falar em linguagens, quando a BNCC adota somente uma LE como base na construção de um conhecimento tão plural e diversificado?

Para as LE, especificamente, a Base considera como obrigatória apenas a LI, não citando a possibilidade de outras línguas serem tratadas no currículo básico do Ensino Fundamental. Tal questão desperta uma discussão polêmica e, minimamente, preocupante em face a uma proposta de relações possíveis entre as LE e a escola pública como ambiente de formação cidadã.

No que trata do ensino e aprendizagem de LI, a BNCC traz a globalização como mola propulsora para o tratamento mais cuidadoso com a língua. No entanto, quando aborda competências específicas para essa LE no Ensino Fundamental, o documento traz uma perspectiva da língua enquanto instrumento, ao afirmar: 
Comunicar-se na Língua Inglesa, por meio do uso variado de linguagens em mídias impressas ou digitais, reconhecendo-a como ferramenta de acesso ao conhecimento, de ampliação das perspectivas e de possibilidades para a compreensão dos valores e interesses de outras culturas e para o exercício do protagonismo social (BRASIL, 2017, p.244, grifo nosso).

Assim, é possível perceber que embora se proponha o exercício do protagonismo social, a competência traz a linguagem como ferramenta para o acesso ao conhecimento. A discussão acerca da língua enquanto mero acessório e utilitarismo comunicativo diz respeito a décadas anteriores no que tange ao histórico da formação docente desta área em nosso país, conforme comentado anteriormente. Além disso, não considera a LI como o próprio conhecimento, no qual são tratados aspectos linguísticos, discursivos e principalmente culturais e ideológicos, que desenham a construção de sentidos dessa língua em seu contexto social de utilização.

Diante desse cenário, de reflexões e mudanças nas políticas para a construção de um currículo para a Educação Básica no Brasil, se faz necessária uma discussão acerca do processo de ensino e aprendizagem de LE e sua relação com a escola pública. Mantendo o foco nas questões políticas e ideológicas que permeiam esse ensino, nos valemos de Rajagopalan,

Trata-se, especificamente, de política linguística. E a dimensão política do ensino de idiomas salta aos olhos desde o estágio do planejamento linguístico, uma tarefa que fica a cargo das mais altas instâncias da administração pública, mas que desemboca nas práticas diárias dentro da sala de aula, antes passando pela questão da escolha dos materiais didáticos (RAJAGOPALAN, 2011, p.61).

Acrescentaríamos a esta citação, a urgência na formação docente dos professores de LE, pois é através de uma formação crítico-reflexiva que se desenvolvem estratégias para lidar com uma diversidade de letramentos necessários a uma participação social mais efetiva e transformadora. O planejamento de uma política linguística, que leve em conta a vivência social dos sujeitos e suas percepções sobre si mesmos dentro dos contextos discursivos mais variados, traz para o ambiente da sala de aula oportunidades para se refletir sobre as práticas sociais letradas e a construção de significados dentro de um contexto cultural e ideológico. 
Assim, a formação do professor na perspectiva do Letramento possibilita o tratamento com o ensino e aprendizagem, considerando as construções culturais e ideológicas que permeiam os diversos contextos discursivos, pois como defende Bunzen,

[...] vivemos práticas sociais concretas em que diversas ideologias e relações de poder atuam em determinadas condições, especialmente se levarmos em consideração as culturas locais, questões de identidade e as relações entre os grupos sociais (BUNZEN, 2014, p.9).

Nesse sentido, o trabalho com as línguas deve considerar as práticas sociais das quais os sujeitos fazem parte e se constroem enquanto cidadãos protagonistas dessas práticas nos mais diversos contextos discursivos. Em vista disso, questionamos o ensino e aprendizagem de LE numa perspectiva instrumental, e reiteramos a importância de políticas públicas focadas na construção do conhecimento linguístico considerando os aspectos sociais, culturais e ideológicos que permeiam as relações discursivas. Sendo, portanto, essas políticas responsáveis pela formação de um professor crítico, reflexivo e consciente do seu papel social e dos impactos de sua atuação para a formação cidadã.

\section{O ensino de Francês na RME de Porto Alegre}

Na década de 90, através da iniciativa da Secretaria Municipal de Educação de Porto Alegre (SMED/PoA), tendo por secretária Esther Pillar Grossi, foi introduzido um projeto de Língua Francesa. Situadas em zonas de alta vulnerabilidade social, as escolas municipais de ensino fundamental (EMEF), âmbito de atuação dessa rede de ensino, passaram a oferecer o projeto intitulado "Francês em Classes Populares", que era acompanhado por alguns professores de português, com dupla licenciatura, ou seja, Português/Francês, já efetivos da rede, e ministrados por alunos dos cursos de Letras das universidades, que realizavam assim um estágio voluntário nessa língua. A iniciativa contemplava também a expectativa d'analyse du terrain (BLANCHET \& CHARDENET, 2011), isto é, de conhecer melhor as comunidades, a fim de serem vislumbradas posteriormente a realização de novos concursos para professores e o atendimento às comunidades escolares que assim assinalassem a necessidade de ensino do Francês enquanto Língua Estrangeira (FLE). 
Como abordamos neste artigo, trabalhar línguas pelo viés do Letramento ${ }^{2}$ significa trabalhar valores humanos que aportam resultados positivos para a sociedade como um todo, não se situando no esquema capitalista de mero serviço no mercado de trabalho e da língua como simples instrumento, já que reverbera em aspectos culturais, sociais e históricos. Discussão semelhante se pensarmos no alcance incomensurável que a filosofia, as artes e a sociologia têm na formação de cidadãos do mundo.

A esse projeto viria a somar-se, na década seguinte, a criação de uma coordenação de LE para o atendimento das três línguas da rede, quais sejam: o Inglês, o Espanhol e o Francês. Essa coordenação foi responsável por realizar, dentre outras ações de planejamento e política linguística, o levantamento do número de alunos, professores e escolas que trabalhavam com as referidas LE, promovendo um mapeamento deste quadro na RME. A título de ilustração, resumimos aqui os dados referentes ao quantitativo de alunos. Tais informações apontam números expressivos para uma rede pública municipal de ensino: 14.935 alunos com Inglês, 13.005 com Espanhol e 3.932 com o Francês (GALLI, 2011, p. 30 e 31).

Em 2005, mesmo ano em que é sancionada a lei que previa a obrigatoriedade do Espanhol a partir de 2010, no Ensino Médio, a criação de uma Coordenação de LE, como anunciado há pouco, tinha dentre seus objetivos integrar as três línguas da rede, além de consolidar o Espanhol junto às escolas de Ensino Médio. À época eram três unidades, além das escolas noturnas que atendiam à Educação de Jovens e Adultos (EJA) e que gozavam igualmente dessa realidade para as LE.

Como comentado na seção anterior, o fato de os municípios usufruírem de uma maior autonomia para a discussão local dos currículos escolares possibilitou que, juntamente à implementação mais sistemática do Espanhol nessa RME, a partir de 2005, fossem também realizados dois outros projetos pertinentes às comunidades escolares da região, ou seja, a inserção do Italiano e do Alemão. Através da LDBEN 9394/96, Artigo 26, parágrafo quinto que versava sobre o fato de que na parte diversificada do currículo "seria incluído, obrigatoriamente, a partir da quinta série, o ensino de pelo menos uma língua estrangeira moderna, cuja escolha ficaria a cargo da comunidade escolar e dentro das

\footnotetext{
${ }^{2}$ Optamos por empregar o termo "letramento" sem os adjetivos crítico e social, ou ainda sem seus possíveis desdobramentos como, por exemplo, multiletramentos, por entendermos ser intrínseco a essa noção seu caráter crítico, social e múltiplo.
}

Revista Investigaç̃̃es, Recife, v. 32, n. 2, p. 456 - 478, Dezembro/2019 
possibilidades da instituição", foi possível implementar essas duas ações para políticas públicas em LE.

Nessa lei de 1996, ao estar previsto o ensino de uma LE na escola pública a partir do quarto ano (B1o) da escola ciclada ${ }^{3}$, termo em contraposição à escola seriada, era possível responder às demandas locais de acordo com suas respectivas realidades. Foi dessa forma que foram inseridos o Italiano e o Alemão no próprio currículo escolar. Ambos foram introduzidos inicialmente sob a forma de oficinas extracurriculares, respondendo à proposta de turno integral, objetivado por dois programas federais vigentes à época (2005 a 2010) "Mais Educação" e “Escola Aberta”.

O primeiro previa atendimento escolar integral, possibilitando que oficinas de Língua Italiana ocorressem no contraturno das escolas participantes do projeto inicial, sendo realizadas de 2005 até sua efetiva implantação em 2010, quando houve o primeiro concurso público para professor de Italiano. O segundo programa federal, "Escola Aberta", previa o atendimento às comunidades do entorno das escolas aos sábados e domingos, uma vez que, pela vulnerabilidade da localização destas unidades escolares, restavam como único espaço de socialização durante os finais de semana. Ocorrendo de forma mais tímida e, sobretudo por meio da "Escola Aberta", a introdução da Língua Alemã nas escolas da periferia porto-alegrense aconteceu a partir de 2007.

Para ambos os projetos, muitas formações foram oferecidas aos professores da RME, desde cursos na própria língua, tendo por parceiros a ACIRS - Associação Cultural Italiana do Rio Grande do Sul e o Instituto Goethe, além da vida associativa das cinco línguas respectivas como: a ARPA - Associação Rio-grandense de Professores de Alemão, a ARPI - Associação dos Professores de Italiano, a APFRGS - Associação dos Professores de Francês do Rio Grande do Sul, o CORPE - Conselho Regional de Professores de Espanhol e a APIRS - Associação de Professores de Inglês do Rio Grande do Sul e todos os respectivos consulados vinculados a essas LE.

O breve resgate quanto à trajetória de algumas ações de políticas públicas para as LE no sul do Brasil permite-nos situar a problemática da formação dos professores em

\footnotetext{
${ }^{3}$ Respondendo à demanda das escolas por ciclos de formação, os quais corresponderiam aos ciclos da vida escolar, as EMEF constituem-se em seis anos do Ensino Fundamental, quais sejam: três anos em cada ciclo assim distribuídos: A10, A20 e A30; B10, B20 e B30 e C10, C20 e C30, configuração em que se prevê o ensino de LE a partir das B10, ou seja, quarto ano das escolas municipais desta rede de ensino.
} 
línguas como central, além de questionarmos mais uma vez o que se entende por Base Nacional Comum Curricular quando se desconsidera o histórico de anos de luta para a consolidação de políticas públicas em LE. Tal percurso dialoga com a representação e as formas do discurso que essas línguas acabam por resplandecer em seus usuários, daí passarmos para a última seção deste artigo, antes das conclusões, buscando problematizar que outras relações além das existentes seriam possíveis entre as LE e a escola pública.

\section{Que relações além das existentes são possíveis entre LE e escola pública}

Antes de tentarmos responder a essa difícil questão, pensamos que seja oportuno discorrer um pouco sobre o termo política linguística empregado aqui. Remetendo-nos mais uma vez à pluralidade que o ensino de LE pressupõe, entendemos que a Educação Básica teria por responsabilidade pública e social oferecer aos estudantes a possibilidade de sensibilização a uma gama de LE minimamente condizente com a contemporaneidade desse conhecimento linguístico (GALLI, 2017b). Apesar de beber da fonte de Louis-Jean Calvet sobre "políticas linguísticas" (2007), o uso do termo aqui se desenha de forma peculiar no tocante à discussão do que sejam essas políticas para as LE no Brasil. Assim, o Letramento em Línguas que se sustenta na abordagem cultural do ensino e aprendizado de LE se apresenta como uma ação de política pública no sentindo de diversificar as línguas propostas pela escola pública. A entrada cultural atravessada por essa abordagem teórico-metodológica preconiza as línguas pelo seu viés de representação social (CHARAUDEAU, 2007), colocando em xeque os propósitos do que seja ensinar e aprender LE na escola. Ainda que teóricos defendam a predominância das competências relativas à ordem do escrito: ler e escrever, na ótica do Letramento em Línguas, não há como dissociar um conhecimento tão complexo como é a construção e aquisição do saber em LE, prescindindo das competências relativas à oralidade.

Há uma ideia global quando se mergulha no processo de línguas que, somente para fins didáticos é distribuído em competências, quais sejam: leitura/escrita e escuta/expressão oral, mas uma não consegue se fazer adequadamente sem a devida participação da outra. Nesse sentido, vem a somar-se uma quinta competência que, em termos de políticas públicas linguísticas para LE é fundamental, trata-se da competência 
intercultural (CI), que permite ao aprendente, ou aprendiz para usar a nomenclatura da LI, uma maior aproximação com a LE através do sentido apreendido em sua abordagem cultural. Não restando mera estrutura ou código, mas assentando-se no que é mais peculiar em termos de construção do conhecimento em LE, a representação que evoca o imaginário e os estereótipos da língua em questão (GALLI, 2018) permite uma abordagem mais totalitária da língua em estudo.

Não pretendemos aqui, entretanto, desenvolver a dimensão conceitual do Letramento em LE, já que não é essa a proposta do artigo, mas tão somente apresentá-la a fim de entender que essas cinco competências estão na base do Letramento em Línguas. Tal concepção é importante no ensino e aprendizado de qualquer língua, sobretudo na escola pública, além disso, é importante também ter em mente que os propósitos não podem se situar exclusivamente no âmbito de "saber somente ler na língua". Muito mais que instrumentalizar, os objetivos de ensino de LE na escola pública devem assentar-se na introdução à cultura diversa que emerge ao estudar-se uma língua outra, evocando noções relativas à alteridade e ao respeito mútuos.

Sob tal perspectiva, vale entender onde se situa o Letramento em Línguas no campo das ciências da linguagem, uma vez que se trata de uma construção contemporânea para essa área de estudos. Formulado por Bryan Street na década de 9o, em linhas gerais, o letramento em línguas ocorre como acontecimento social situado historicamente, contextualizando política e cultura como vieses que atravessam o discurso das LE, já que analisa relações de poder na constituição identitária dos sujeitos.

O referido estudioso, ao realizar pesquisas no âmbito de comunidades minoritárias, e muitas vezes analfabetas (para os cânones ocidentais), traz à discussão o fato deste conhecimento ter implicações discursivas e sociais que colocam o letramento junto às demais correntes. Movimentos intelectuais que contrapõem uma visão exclusivamente estruturalista da língua enquanto sistema, operando em sua investigação como uma entidade não somente formal e sistemática. Nesse sentido, verificamos aproximação epistemológica do Letramento em LE com os fundamentos da Teoria Crítica, tida como um movimento mais amplo ocorrido nas Ciências Humanas e Sociais. Sobre este tema, cabe ressaltarmos a contribuição de Silva (1999) ao analisar a produção do currículo escolar como fonte de críticas e reflexões sociais. 
De acordo com Tomaz Tadeu Silva, em sua obra Documentos de Identidade (1999), as construções dos currículos são verdadeiros focos de estudo para as ciências humanas em suas mais diversas expressões. A massificação da escola repercutiu também nos conteúdos e programas, restando um percurso com marcas históricas e sociais muito alarmantes na análise do que seja pertinente estar ou não no currículo escolar. Nesse sentido, nos perguntamos onde estariam as LE? Das teorias tradicionais do currículo às teorias críticas e às teorias pós-críticas, abordagens pós-coloniais vale a reflexão do lugar que as línguas sempre ocuparam no currículo das escolas públicas brasileiras.

Juntamente às Teorias do Currículo, vinculadas à Educação (ressaltamos no início do trabalho a proximidade entre Letras e essa área), outras perspectivas de estudos das ciências humanas e sociais vem a somar-se à contemporaneidade do que seja ensinar e aprender línguas na escola pública. A Análise do Discurso francesa, a História das Ideias Linguísticas, cujos maiores expoentes são Michel Pêcheux e Eni Orlandi, ambos da década de 1980, a Semântica do Acontecimento e os Estudos Pós-Coloniais configuramse como aportes teóricos que dialogam com o Letramento em LE, dada a semelhança de concepção dessas abordagens no que tange, sobretudo, ao trato discursivo e ao fato de não beber unicamente de teóricos estrangeiros para estudar fenômenos locais, como é o caso do ensino e aprendizado de LE no Brasil. Nesse sentido, o Letramento em Línguas tem atuação direta no discurso escolar, realizando-se no contato explícito da prática pedagógica, daí sua vinculação com a LA, pela autonomia e pelas premissas teóricas que caracterizam essa área do conhecimento, reconhecendo o Letramento em LE no Brasil como uma vertente contemporânea da LA.

Em tal fundamentação teórica vale comentarmos sobre os postulados de Magda Soares (2017), propagadora do letramento no Brasil. Com vistas a nomear esse fênomeno distinto da alfabetização, é em meados de 80 que acontece a 'invenção' do letramento no Brasil, do lettrisme ou littératie, na França, da literacia, em Portugal. Já nos EUA e na Inglaterra, apesar da existência anterior do termo literacy, será também por essa época que a expressão ganhará discussões locais, em contraposição à alfabetização.

Cabe registrarmos igualmente que o desenvolvimento de seu trabalho está centrado majoritariamente na distinção entre alfabetização $\mathrm{x}$ letramento escolar, considerando as competências relativas à escrita conforme o fato de que "a alfabetização é um processo de representação de fonemas em grafemas, e vice-versa, mas é também um 
processo de compreensão/expressão de significados por meio do código escrito" (SOARES, 2007, p. 17, grifo da autora). Dessa forma, é possível entrever a aproximação deste letramento com o letramento aqui discutido, o Letramento em Línguas. Vemos assim a natureza interdisciplinar dessa área em pleno desenvolvimento, tanto pelo diálogo permanente que estabelece com áreas afins quanto pela qualidade crítica de intervenção que apresenta enquanto fonte de conhecimento.

À guisa de conclusão, reconhecem-se os esforços em todos os âmbitos educacionais para os avanços de políticas em LE, seja em municípios, os quais gozam de maior autonomia para implantação de políticas linguísticas, de acordo com o que foi possível verificar na RME aqui relatada, seja em estados como ações empreendidas ao longo dos anos, como em Pernambuco, especialmente através da LA, como atesta Bohn (2005), por sua inserção enquanto campo do saber transversal. Sob tal percurso histórico, retomamos, entretanto o IsF, por entendermos que esse programa trouxe uma envergadura nacional às propostas de ensino de línguas na esfera pública, à formação de professores e à pesquisa acadêmica.

Nesse sentido, vale a leitura do capítulo intitulado "A área de política e planejamento linguístico: as práticas de pesquisa”, organizado por Souza et al (2019), já que o mesmo faz um apanhado importante entre teorias em política e planejamento linguístico, no qual destacam o cenário teórico acerca desse tema no Nordeste. Neste capítulo, vale observar, dentre outros, que houve nos últimos anos uma produção em pesquisas de cunho linguístico envolvendo o IsF. Tal constatação permite afirmar que em todas as áreas, mas particularmente na de professores de línguas, pesquisa e formação restam um binômio indissociável para os avanços de políticas públicas linguísticas de LE. Observando a orientação teórica nas teses, dissertações e artigos da região em um recorte temporal que remete aos últimos 20 anos, é possível reconhecer avanços no tocante ao tema língua e cidadania, cerne do Letramento em LE.

Não mera coincidência, o fato é que nunca se produziu tanto sobre o tema de ensino e pesquisa sobre LE no Brasil como no período referendado. Apesar de seus limites, o programa IsF teve sua contribuição para esse impacto na sociedade civil quanto à pertinência de se estudar línguas nas universidades e institutos federais, ou seja, na educação pública. 


\section{Considerações finais}

A título de conclusão, somos conscientes da inconclusão de uma temática tão profundamente arraigada à memória e ao coletivo dessa nação miscigenada que é o Brasil. No entanto, é possível afirmar que o apagamento de uma lei que oferecia às comunidades escolares a possibilidade de escolha de uma LE mais relevante ao seu contexto junto à imposição de uma única língua como sinônimo de LE no documento norteador brasileiro, a Base, restam minimamente como retrocessos. Debate importante dentro dos avanços empreendidos nos últimos anos tanto no que tange à formação de professores quanto às políticas linguísticas vigentes em LE (a formação de professores pode também ser encarada como uma ação de política linguística, porém este seria assunto para outro artigo).

A respeito especialmente da BNCC, homologada em dezembro de 2017, devemos nos questionar se esse documento que se propõe a ter a mesma base nacional comum curricular oferecerá as mesmas oportunidades para a construção desse conhecimento, no caso a LI? Ora, compreendida como uma LE no campo dos estudos da linguagem, por ser antes estranha e não mera adição à formação cidadã, o fato de rechaçar as demais línguas comuns até então aos currículos escolares, como Espanhol, Francês, Italiano e Alemão, permite respondermos que se equivoca desde a sua concepção. Nenhum imaginário sobre democracia e cidadania entende a eleição de uma única LE como o ideal de construção de conhecimento linguístico em uma base que se pretende comum e nacional.

Tentamos responder assim à pergunta da seção anterior de forma afirmativa, não sem entender os limites de uma resposta que pode parecer simplificadora, mas há de se buscar outras relações possíveis entre LE e escola pública. Certamente trata-se de um exercício de alta complexidade discutir a formação de professores de línguas em um país tão grande quanto o Brasil, que deveria contemplar também o ensino e aprendizado de outras línguas pertinentes às comunidades escolares, pois viver o sentido da construção e aquisição desse conhecimento resplandece em atitudes curriculares transversais e, como diria Moita Lopes, (in)disciplinares.

O desconhecimento dos esforços empreendidos para a formação docente em línguas e o apagamento literal da LDBEN 9394/96, impondo-se o Inglês como sinônimo 
único e exclusivo de LE em um documento que se pretende a Base Nacional Comum Curricular, tornam essa discussão um debate coletivo importante para os avanços na construção do conhecimento em línguas no Brasil.

\section{Referências}

AUBIN, S. \& GALLI, J. 2015. Motiver à l'enseignement du français au Brésil. In: Le Français Dans Le Monde. Numéro 397/Janvier-Février. Paris: CLE International. P. 34 et 35.

BLANCHET, P. CHARDENET, P. Guide pour la recherche en didactique des langues et des cultures. Approches contextualisées. Paris: Éditions des Archives Contemporaines, 2011.

BOHN, H. I. As exigências da pós-modernidade sobre a pesquisa em Linguística Aplicada no Brasil. In: FREIRE, M. et al. Linguística Aplicada e Contemporaneidade. São Paulo: ALAB; Campinas, SP: Pontes Editores, 2005, p.11-23.

BRASIL. Lei de Diretrizes e Bases da Educação Nacional. Lei número 9394, 20 de $\begin{array}{llll}\text { dezembro de } & 1996 . & \text { Disponível }\end{array}$ <http://portal.mec.gov.br/index.php?option=com_content\&view=article\&id=12907:legis lacoes\&catid=70:legislacoes $>$. Acesso em: 28 de novembro de 2019.

. Ministério da Educação. Base nacional comum curricular. Brasília, DF: MEC, 2017. Disponível em: <http://basenacionalcomum.mec.gov.br/>. Acesso em: 28 de agosto de 2018.

. Ministério da Educação. Secretaria da Educação Média e Tecnológica. Parâmetros Curriculares Nacionais: Ensino Fundamental. Brasília: Ministério da Educação, 1998.

Orientações Curriculares para o Ensino Médio: Linguagens, Códigos e suas Tecnologias. Brasília. Ministério da Educação, 2006. 
BUNZEN, C. Apresentação. In: STREET, Brian. Letramentos sociais. abordagens críticas do letramento no desenvolvimento, na etnográfica e na educação. Trad. Marcos Bagno. São Paulo: Parábola Editorial, 2014.

CALVET, L-J. As políticas linguísticas. São Paulo: Parábola Editorial: IPOL, 2007.

CHAURAUDEAU, P. Les stéréotypes, c'est bien. Les imaginaires, c'est mieux in Boyer H. (dir.), Stéréotypage, stéréotypes: fonctionnements ordinaires et mises en scène, L'Harmattan, Paris, 2007.

COLEÇÃO PROFESSOR CARLOS MACIEL: Subsídios para organização da prática pedagógica nas escolas. Língua Inglesa. Secretaria de Educação e Esportes. Diretoria de Educação Escolar. Recife, 1997.

ESTADO DE PERNAMBUCO. Parâmetros para a Educação Básica de Pernambuco. Secretaria de Estado de Educação, 2013.

. Orientações Teórico Metodológicas para o Ensino Médio. Secretaria de Estado de Educação, 2009.

GALLI, J. A. Des représentantions culturelles dans l'enseignement-apprentissage de français: la langue comme signe d'altérité dans le programme Brafitec. In : Mobilités, Réseaux et interculturalités, nouveaux défis pour la recherche scientifique et la pratique professionnelle. Collections Espaces Interculturels. Orgs. COSTA-FERNANDEZ, DENOUX et LESCARRET. Éditions de L'Harmattan, 2018, p. 249-26o.

La notion d'interculturel et l'enseignement-apprentissage des langues étrangères au Brésil: représentations et réalités du français. In: Synergies Brésil - Territoires et expériences de la francophonie en Amérique du Sud et ailleurs. Número 12, GERFLINT, 2017a, p. 81-102. Disponível em: <http://gerflint.fr/Base/Bresilı/armani_galli.pdf>. Acesso em 28 de novembro de 2019. 
Línguas estrangeiras: formação e pesquisa nas Letras, consciência política e social. In: GELNE 40 ANOS: experiências teóricas e práticas nas pesquisas em Linguística e Literatura. São Paulo: Blucher, 2017b, p. 231-252. Disponível em: <file://C:/Users/Joice\%2oArmani\%2oGalli/Downloads/1373.pdf $>$. Acesso em 28 de novembro de 2019 .

As línguas estrangeiras como política de educação pública plurilíngue. In: GALLI et al. Línguas que botam a boca no mundo: reflexões sobre teorias e práticas de línguas. Recife: EDUFPE, 2011, p. 15 - 36.

LAGARES, X. C. Qual política linguística? Desafios glotopolíticos contemporâneos. São Paulo: Parábola Editorial, 2018.

LEFFA, V. J. O ensino de línguas estrangeiras no contexto nacional. Contexturas, APLIESP, n.4, p. $13-24,1999$.

LIBERALI, F. C. Atividade Social nas aulas de língua estrangeira. São Paulo: Moderna, 2009 .

MARCUSCHI, L. A. Produção textual, análise de gêneros e compreensão. 3 ed. São Paulo: Parábola, 2008.

MOITA LOPES, L.P. Por uma linguística indisciplinar. São Paulo: Parábola Editorial, 2006.

RAJAGOPALAN, K. Vencer barreiras e emergir das adversidades com pleno êxito, sempre com o pé no chão. In: LIMA, DC de. Inglês em escolas públicas não funciona. Uma questão, múltiplos olhares. São Paulo: Parábola Editorial, 2011, p. 55 - 65.

SILVA, T.T. Documentos de identidade: uma introdução às teorias do currículo. Belo Horizonte: Autêntica, 1999.

SOARES, M. Alfabetização e letramento. São Paulo: Editora Contexto, 2017.

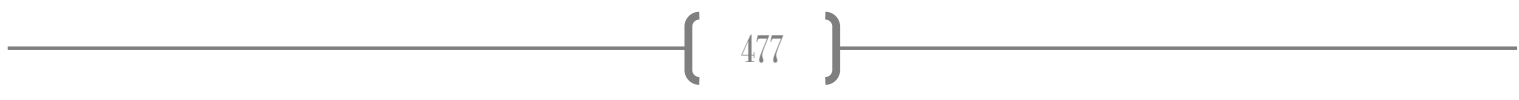


SOUZA et al. A área de política e planejamento linguístico: as práticas de pesquisa. In: ATAIIDE, C. Cartografia GELNE: 20 anos de pesquisas em linguística e literatura no NE: um mapeamento das microáreas. São Paulo: Editora Contexto, 2019.

STREET, B. Letramentos sociais: abordagens críticas do letramento no desenvolvimento, na etnográfica e na educação. São Paulo: Parábola Editorial. 2014.

\footnotetext{
* Mestre em Linguística pela Universidade Federal de Pernambuco e professora de inglês no IFPE.

${ }^{* *}$ Professora de francês na Universidade Federal Fluminense (UFF). É formada em Língua e Literatura Portuguesa e Francesa pela PUCRS e Doutora em Linguística pela UFRGS e líder do grupo de pesquisa Lenuffle.
} 